\title{
Water-resistant gypsum binder
}

\author{
Alexander I. Panchenko ${ }^{1, *}$, Nikita Kozlov $^{2}$ \\ ${ }^{1}$ Prof. Chair of binding agents and concrete, Moscow State University of Civil Engineering, \\ 26, Yaroslavskoye Chausse, Moscow, Russian Federation \\ ${ }^{2}$ Director, "Promressurs" Co. Ltd. Moscow, Russian Federation
}

\begin{abstract}
The authors developed a multi-component gypsum binder (MGB) with an improved (by 1.8 to 2.2 times) water resistance value in comparison with the initial gypsum and a softening factor value within the range of 0.85 to 0.91 through the introduction of a complex additive containing carbide mud and bio-silica. The use of a complex additive provides for the formation of a denser structure due to the formation of low-base calcium hydrated silicates at early stages of the hardening process under wet or dry air conditions. The developed binding agent has a lower (by 2.5 to 3 times) open porosity, a greater compressive strength (by 1.4 to 1.6 times for a dry state and by 2.6 times in a water-saturated state) and does not require any special curing conditions in contrast to the other multi-component gypsum binders. The authors show the influence of mudand-silica additive on the properties of hardened MGB and suggest a method of computation of the optimum MGB composition for given components.
\end{abstract}

\section{Introduction}

The expansion of the field of the use of gypsum binder (GB) as the materials for fencing structures is rather promising due to the abundance of gypsum stone deposits, waste products containing gypsum as well as a simple production technology and a low energy consumption. One more advantage of gypsum binder is a higher hardening rate under dry air conditions in comparison with the Portland cement. The disadvantages of gypsum binder are: a sharp decrease in strength when moistening, a low resistance to environmental impacts and a high creep value, i.e. a low operation reliability [1].

One of the ways to improve the operation reliability is the reduction of gypsum solubility in combination with the modification of the porosity. The use of carbide mud (a waste by-product from the acetylene production process) and bio-silica as the components guarantees considerable engineering, economic and environmental effects as the acetylene production in the Russia (400,000 tons in 2013) gives more than 1,000,000 tons of carbide mud yearly $(1,140,000$ tons in 2013) [2].

\section{Experimental studies}

\subsection{Raw materials}

\footnotetext{
*Corresponding author: alex250354@gmail.com
} 
The research works were carried out with the use of the following materials:

1. Semi-hydrated gypsum;

2. Silica containing components (micro-silica and bio-silica);

3. Carbide mud;

4. Portland cement;

5. Retarder agent;

6. Plasticizer.

\subsection{Process of the experiment}

In the process of experimental studies, the authors prepared the samples from gypsum binder, carbide mud, silica containing components (micro-silica and bio-silica) and plasticizer. The samples were subject in various environments according to experimental conditions within the curing period until 28 days. The produced samples were mainly beams $(4 \times 4 \times 16 \mathrm{~cm})$, the curing process lasted 28 days. All the gypsum binder compositions were produced in accordance with requirements of the standard GOST 23789-79* "Gypsum binding agents. Test methods". The softening factors for gypsum binder were determined in accordance with the TU 21-31-62-89 normative document.

\section{Results and discussion}

The experiments showed that the optimum ratio values (with respect to the improvement of water resistance and strength of the material) turned out to be the following: the microsilica to carbide mud ratio in the mud-and-silica additive equaled 1.0 to 1.2 and the biosilica to carbide mud ratio equaled 0.5 to 0.7 (Fig 1,). Thus, the consumption of bio-silica was by 1.8 times less than that of micro-silica [2].

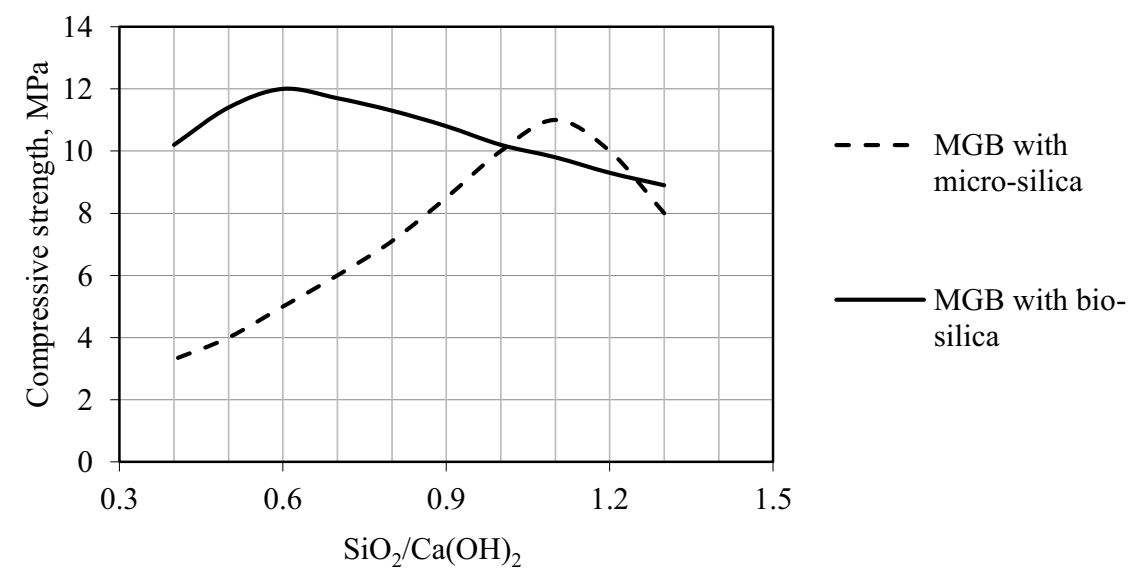

Fig. 1. Compressive strength in a water-saturated state for the MGB (multi-component gypsum binder) samples depending on the $\mathrm{SiO}_{2} / \mathrm{Ca}(\mathrm{OH})_{2}$ ratio. 


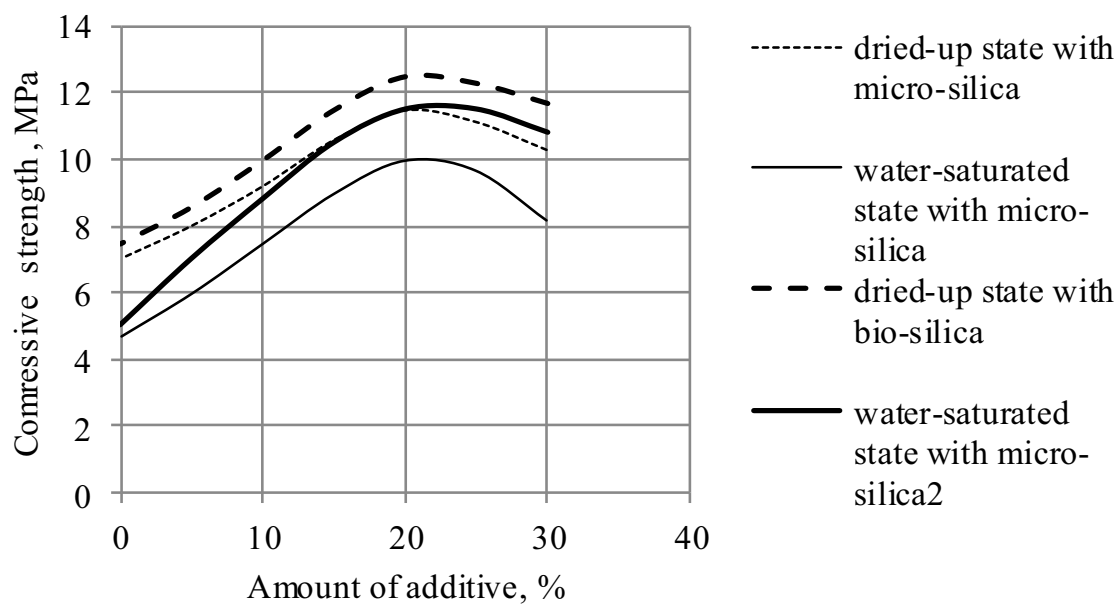

Fig. 2. Compressive strength depending on the amount of additive.

The optimum amount of additive in gypsum equals 18 to 22\% (mass) (Fig. 2). The use of multi-component gypsum binder as a part of the micro-silica additive may improve the strength of the material by 1.6 times (water-saturated state) and by 1.1 times (dry state), respectively. The use of the bio-silica additive improves the material strength by 2.6 and 1.4 times, respectively (Fig. 3).

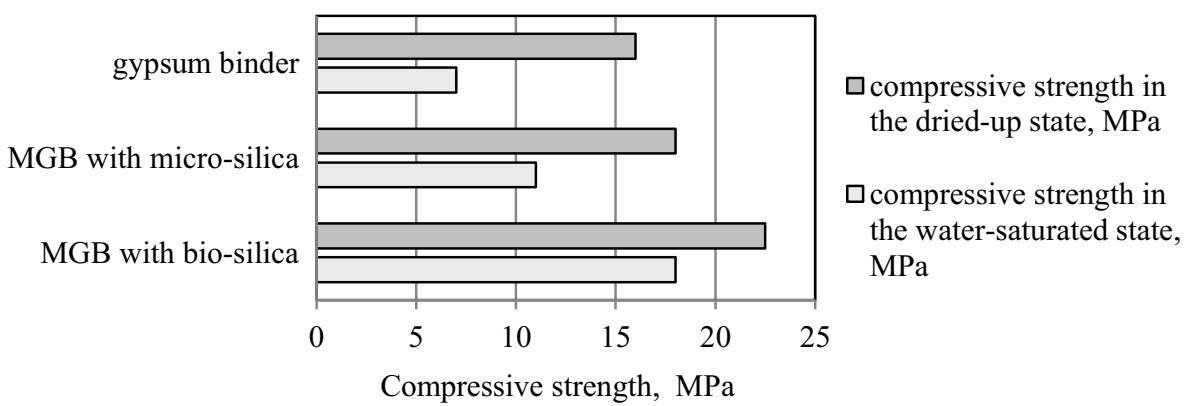

Fig. 3. Comparison of efficiency of the use of micro-silica and bio-silica as the components in a mudand-silica additive.

The authors studied the influence of the hardening process on the MGB properties. The following curing procedures were used:

1. Natural dry atmosphere (NDA) during 28 days;

2. Thermal-and-moisture treatment (TMT) at the temperature of $80^{\circ} \mathrm{C}$ during 8 hours;

3. Normal conditions (NC) (normal hardening chamber) during 28 days.

The production of a material with an improved water resistance requires a thermal-andmoisture treatment of the material or its cure under normal conditions. The use of mud-andsilica additives based on the bio-silica does not require any special hardening conditions. In the process of hardening of these additives under natural dry conditions, the softening factor only slightly decreases, and its value is not less than 0.85 (Fig.4).

Fig. 4 shows that the use of bio-silica as an additive component reduces the change in the softening factor by 3.6 times with respect to the micro-silica. The reduction of the softening factor value for a bio-silica additive equals $5 \%$, while that for a micro-silica 
additive is $18 \%$. Thus, the use of MGB with bio-silica does not require any special hardening conditions.

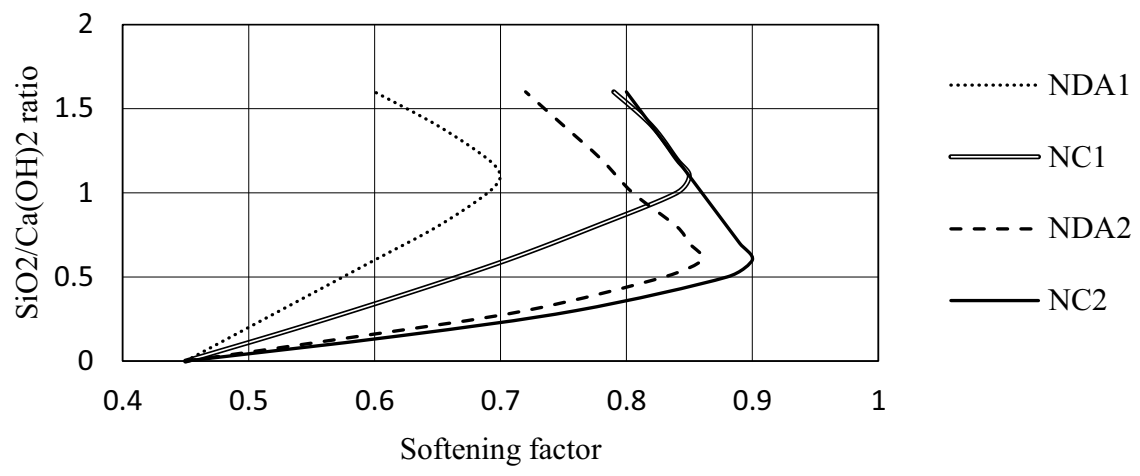

Fig. 4. Change in the strength values for water-saturated samples: 1 - MGB with micro-silica; 2 MGB with bio-silica for various hardening conditions depending on the $\mathrm{SiO}_{2} / \mathrm{Ca}(\mathrm{OH})_{2}$ ratio in the additive.

In addition to that, the use of bio-silica reduces the material cost and so improves its economic efficiency. The cost of the mud-and-silica additive based on the bio-silica is by 2.4 times lower than that of an additive based on the micro-silica. The studies proved the efficiency of bio-silica, therefore the further research works consider the bio-silica to be the main silica component $[3,4]$.

A slow drying rate for MGB samples may prove the fact that the material structure has less pores and capillaries, i.e. the overall porosity is smaller. So the moisture loss from the material is less and the reactions with the formation of calcium hydrated silicates proceed earlier. It may be explained by a high rate of absorption of the carbide mud by the biosilica; the absorption value after 30 days is by 4 times higher than that for natural active additives, and it is by $60 \%$ higher than the micro-silica activity. The studies showed that in addition to a high activity value for the age of 30 days, an intensive absorption of carbide mud during the first 3 days for the bio-silica takes place with the formation of calcium hydrated silicates. It causes the formation of a finer porous structure and the reduction of the rate of water removal from the hardened stone during the initial curing period, which, in turn, provides for a more complete proceeding of reactions between bio-silica and carbide mud without wet hardening conditions in contrast to the hardening gypsum stone with a micro-silica additive.

The studies of porous structure of the MGB samples at the age of 3 days with the use of a specific surface analyzer as well as the studies of the pore size values and their volume distribution performed through the standard porosimetry method proved the hypothesis of a fine porous material structure.

Table 1. Porosity of produced samples

\begin{tabular}{|c|c|c|c|c|}
\hline \multirow{2}{*}{ Samples } & \multicolumn{4}{|c|}{ Porous structure } \\
\cline { 2 - 5 } & Total pores (P), \% & Open pores $\left(\mathrm{P}_{\mathrm{O}}\right), \%$ & $\mathrm{P}_{\mathrm{O}} / \mathrm{P}$ & $\begin{array}{c}\text { Predominant pore } \\
\text { size, } \mu \mathrm{m}\end{array}$ \\
\hline GB & 36.2 & 25.2 & 0.7 & $0.003-0.1$ \\
\hline MGB & 37.1 & 15.3 & 0.42 & $0.001-0.005$ \\
\hline
\end{tabular}


The porous structure of MGB considerably differs from the initial gypsum structure: the number of open pores in a hardened MGB is by 1.5-3 times less than that in hydrated gypsum. The hardened MGB has a fine porous structure: the predominant pore size is $0.001-0.005 \mu \mathrm{m}$ in comparison with $0.003-0.1 \mu \mathrm{m}$ for hardened hydrated gypsum. So, the micro-pore concentration for hardened GB is about $50 \%$ (volume), and for hardened MGB it is about $80 \%$ (volume); this fact may be a precondition for the improvement of water resistance and frost resistance of MGB as well as of the concrete based on them.

The X-ray phase analysis (Figs 6, 7), the scanning electron microscopy (Fig. 8) and the thermo-analysis showed new formations including low-base slightly soluble calcium hydrated silicates consolidating the structure of the MGB material, which improves its water resistance and reduces the creep value in comparison with GB materials.

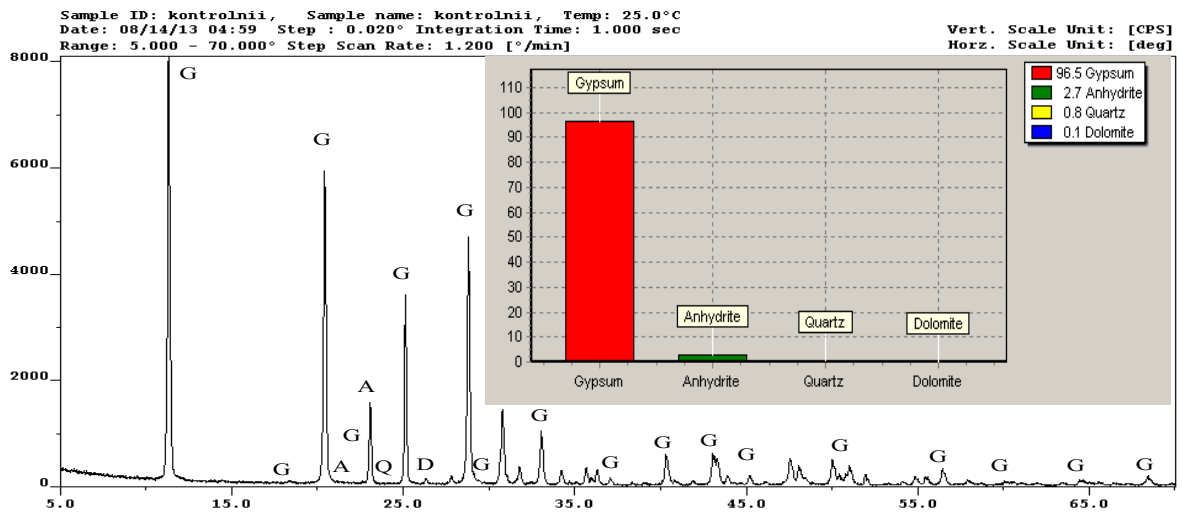

Fig. 6. X-ray diffraction pattern for a GB sample combined with its phase structure: G - hydrated gypsum; A - anhydrite II; Q - quartz; D - dolomite.

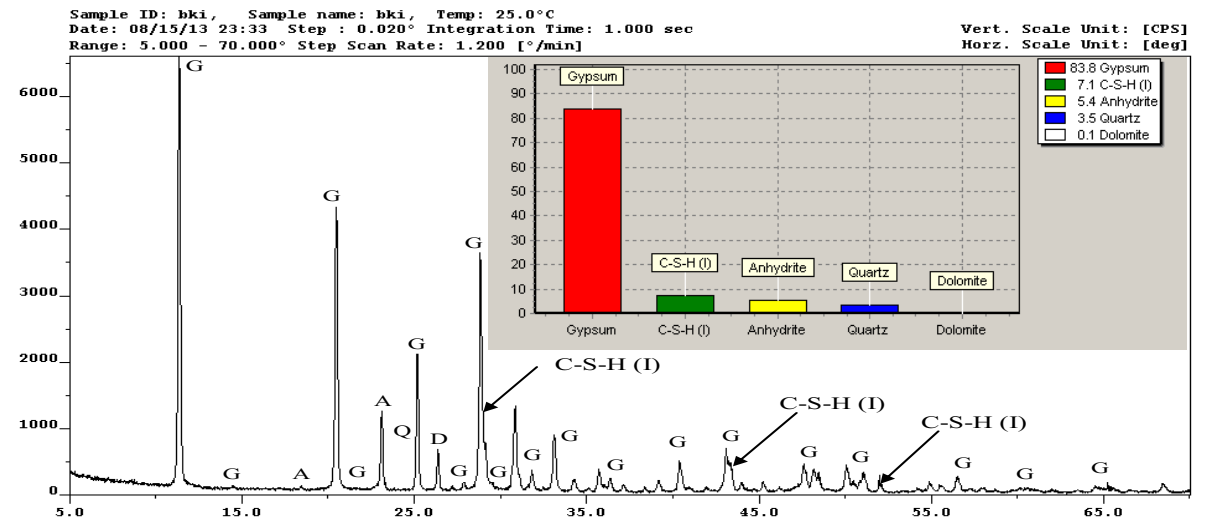

Fig. 7. X-ray diffraction pattern for a MGB sample combined with its phase structure:

G - hydrated gypsum; A - anhydrite II; Q - quartz; D - dolomite; C-S-H (I) - two-base calcium hydro silicate. 
A)

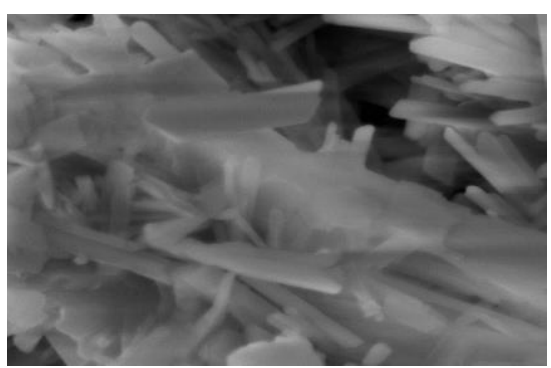

B)

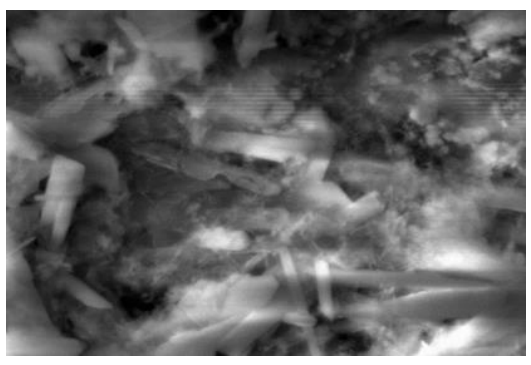

Fig. 8. Scanning electron microscopy of the sample structure (magnification: 5000x): A - GB; B - MGB.

The study of the influence of curing conditions on the properties of hardened MGB showed that there are several variants of the cure of materials: natural dry conditions, normal hardening conditions and thermal-and-moisture treatment. The steam curing is the best way of improvement of water resistance of products, but this method is rather difficult and not always available. Almost the same effect may be achieved by the process of curing of MGB samples under normal conditions during the period of 14 days. In the process of hardening of MGB samples under dry air conditions (14 days), the softening factor only slightly decreases, and its value is not less than 0.85 . Thus, any method is good for the production of water resistant materials.

\section{Conclusions}

The introduction of a complex additive with carbide mud and bio-silica into the two-water gypsum provides for the production of a gypsum binder with improved water-resistance which allows producing structural elements and structures for the operation under wet conditions including the elements for fencing (wall) structures. Here the hardening process for MGB elements does not require any special cure conditions in contrast to the other known gypsum binders.

The use of a complex additive provides for the formation of a more dense structure due to new formations (low-base calcium hydrated silicates), the reduction of open porosity by 2.5 to 3 times and the improvement of water resistance by 1.8 to 2.2 times with the softening factor of up to 0.91 .

Here the compressive strength of the material in water-saturated state becomes by 2.6 times greater.

The intensive interaction of carbide mud with bio-silica during the first 3 days with the formation of low-base calcium hydrated silicates provides for the formation of a fine pores structure and considerably reduces the rate of water removal from the hardening stone during the initial hardening stage which causes a more complete proceeding of reactions between the bio-silica and the carbide mud without wet hardening conditions.

\section{References}

1. Korovyakov V.F., Construction Materials, 3 (2008)

2. Kozlov N.V., Panchenko A.I., Bur'yanov A.F., Solov'ev V.G., Buldyzhova E.N., Gal'tseva N.A, Nauchnoe obozrenie, 9 (2013)

3. Panchenko A.I., Bur'yanov A.F., Solov'ev V.G., Kozlov N.V., Pashkevich S.A., Construction Materials, 12 (2014)

4. Patent 2562621 Russian Federation, Binder, (2014) 